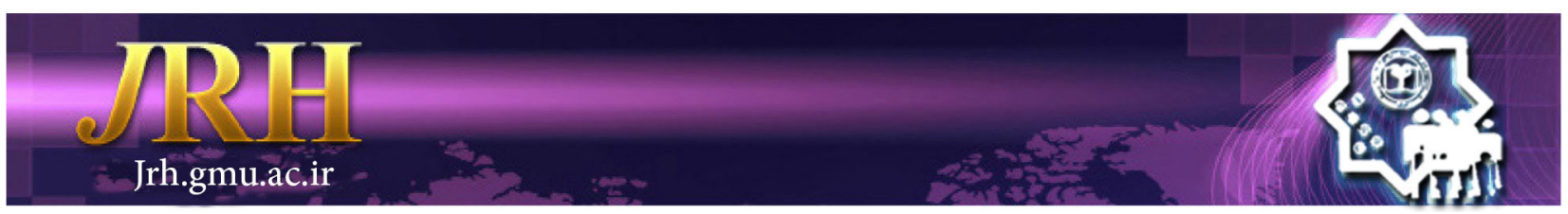

\title{
Effect of mindfulness based on cognitive-behavioral therapy focusing on anger management regarding anxious thoughts among male students
}

Khaled Badpa ${ }^{1}$, Mahmoud Shirazi ${ }^{2}$, Ali Arab ${ }^{2}$

\author{
Journal of Research \& Health \\ Social Development \& Health Promotion \\ Research Center \\ Vol. 9, No.3, May \& Jun 2019 \\ Pages: 220- 226 \\ DOI: $10.29252 / j r h .9 .3 .220$ \\ Original Article
}

1. Department of Psychology, Zahedan Branch, Islamic Azad University, Zahedan, Iran

2. Department of Psychology, Faculty of Psychology, University of Sistan and Baluchestan, Zahedan, Iran

Correspondence to: Mahmoud Shirazi, Department of Psychology, Faculty of Psychology, University of Sistan and Baluchestan, Zahedan, Iran

Email: mshirazi@edpsy.usb.ac.ir

Received: 30 Agu 2018

Accepted: 8 Jan 2019

How to cite this article: Badpa Kh, Shirazi M, Arab A. Effect of mindfulness based on cognitive-behavioral Therapy focusing on anger management regarding anxious thoughts among male students. $J$ Research \& Health2019; 9(3): 220- 226.

\begin{abstract}
Adolescence is accompanied by specific biological, cognitive, and identity changes. A decreased level of tolerance and identity anxieties are among the signs that can emerge during this period and affect students' mental health and their quality of academic life. This study aimed to determine the effect of mindfulness based on cognitive-behavioral therapy focusing on anger management regarding anxious thoughts. This quasi-experimental study used a pretest-posttest design. The statistical population of this study included all male junior high school students studying at high schools in Chabahar. To this end, a corpus of 30 male junior high school students in Chabahar who obtained high scores on wells anxious thoughts inventory were randomly selected and then assigned to two groups of experimental and control (each constituting of 15 participants). The experimental group underwent 10 sessions of mindfulness-based cognitive behavioral anger management therapy and the control group did not receive such a therapy. To collect data for the present study, the wells anxious thoughts inventory was used. Results of the current study showed that the mean score of anxious thoughts obtained by the experimental group was significantly lower than that obtained by the control group in the posttest. The results of this study demonstrated that mindfulness-based cognitive behavioral anger management therapy can decrease anxious thoughts among.
\end{abstract}

Keywords: Anger, Anxiety, Cognitive-Behavioral Therapy, Students

\section{Introduction}

Adolescence is one of the most stressful periods in a person's life. During this period, adolescents may face several academic problems which can affect their quality of personal and academic lives. In this period, adolescents' thoughts, emotional challenges, personality types, moods, and levels of quality of life are quite distinct [1]. Adolescence is accompanied by specific biological, cognitive, and identity changes. A decreased level of tolerance and identity anxieties are among the signs that can emerge during this period and affect students' mental health and their quality of academic life [2]. Anxiety is one of the most prevalent mental health issues during adolescence. It is believed that implementing programs in 
schools aimed at preventing anxiety during childhood and adolescence can bring about several positive mental health-related outcomes. Global programs for preventing anxiety and depression among children are limited. A number of studies are needed to be conducted on programs aimed at preventing anxiety and depression among children and adolescents to examine their long-term effects [3]. Finding a proper solution for treating anxiety has been the focus of attention since Hippocrates. Special techniques have been proposed and used in different ways to treat anxious thoughts, stress, and depression among adolescents [4]. All people experience anxious thoughts in their everyday lives. These thoughts are considered as a component of personality structure which, at a moderate level, can also be regarded as a compromised response. Although low levels of anxiety can be constructive and useful, high levels of anxiety can have a chronic and persistent effect. In that case, not only anxiety cannot be regarded as a compromised response, but also it should be considered as a source of failure, lack of compromise, and widespread frustration which can deprive a person of a large part of his/her capabilities [5]. The prevalence of anxiety in children and adolescents has almost doubled in the last 5 years. Children who live in remote areas are less likely to get access to psychological services and this, on its own, creates a concern about access to health care services [6]. During adolescence, high levels of anxiety are associated with students' emotional challenges, personality types, moods, and quality of life and even adolescents with high levels of anxious thoughts are likely to develop mental and psychological diseases [2]. Anxiety is one of the least characteristics of schizophrenia. Results of a study indicated that anxiety was mainly determined by primary environmental factors as well as socio-cognitive dimensions such as personal difficulties [7]. Anxiety disorders can lead to general anxiety disorder, obsessive-compulsive disorder, panic disorder, social anxiety disorder, and posttraumatic stress disorder [8]. The obsessivecompulsive disorder, post-traumatic stress disorder, and anxiety disorders are among the primary clinical features of anxiety [9]. Levels of cognitive psychological health and quality of life among adolescence can affect development of anxiety among them [10]. Furthermore, social and economic backgrounds of parents are significant predictors of anxiety in adolescent children [11]. Social supports also reduce anxiety among parents and adolescents [12]. Moreover, sensory information can significantly decrease anxiety regardless of methods of dealing with such information [13]. Additionally, identity discrimination leads to anxiety in adolescents [14]. Excessive protections provided by mothers reduce levels of anxiety among children and adolescents [15]. Parents' identification of emotional distress in adolescents is an important factor in early diagnosis and treatment of mental disorders. However, almost no studies have been carried out on parents' and adolescents' agreement on emotional disturbances among adolescents. A significant percentage of adolescents, especially high school students who are exposed to anger, experience some symptoms which are considered normal by their parents. Interventions are needed to help adolescents manage and express their negative emotions. In addition, programs aimed at improving parents' awareness of emotional distress and appropriate behaviors are needed to help adolescents [16]. Hitherto, some studies have examined the role of reinforcing behaviors, parents, and parenting styles in decreasing these behaviors among adolescents; however, quantitative studies are needed to investigate the role of adolescents in this process [17]. Symptoms of depression and impulsivity may be related to cortical thinning in overlapped and distinct regions during childhood and adolescence [18]. This cognitive-behavioral therapy is a potential biological mechanism influenced by psychotherapy that can reduce the negative effects of rumination [19]. Junior high school years are one of the most critical academic periods for students since, during these years, students experience a 
series of biological and cognitive changes. Most academic failures, school dropouts, and behavioral disorders associated with cognitive and identity anxieties occur during this period. Experiencing anxiety disorders is also the main feature of this period. Additionally, different cultural-social and environmental contexts, in which various statistical populations live, affect the formation of anxiety behaviors. In this regard, the objective of the present study was investigating the effect of mindfulnessbased cognitive behavioral anger management therapy on anxious thoughts in male junior high school students.

\section{Method}

This quasi-experimental study was conducted using a pretest-posttest design. The statistical population of this study included all male junior high school students of Chabahar, Southeast of Iran, in the academic year of 2017-2018. According to causal - comparative and experimental research, the sample size of for each group is sufficient [20]. To this end, 30 male junior high school students in Chabahar out of 7460 students who obtained high scores on wells anxious thoughts inventory were selected and then randomly were assigned to two groups of experimental control (each including 15 students). The students had the opportunity to abandon the study whenever they wanted. In this study, the predictive variable was mindfulness-based cognitive behavioral anger management therapy and the criterion (dependent) variable was anxious thoughts. The students did not have history of aggressive behaviors, depression, anxiety, and receiving counseling services in their documents.

To collect data for the present study, the wells anxious thoughts inventory was used [22]. The experimental group underwent 10 sessions of mindfulness-based cognitive behavioral anger management therapy and the control group did not receive such a therapy. A condition for using covariance analysis is to establish the test's assumptions. To examine the normal distribution of scores of dependent variables, the Kolmogorov-Smirnov test was used. Since the significance values of the research variables were greater than $0.05(Z=0.11)$, the zero hypothesis was rejected and the normal distribution of the scores in the pretest and posttest stages was confirmed in the experimental and control groups. To verify the homogeneity of variances in two groups in the pretest and posttest stages, the Levene's test was applied, the results of which indicated that the value of $F$ related to the Levene's test was not statistically significant. The assumption of homogeneity of the regression slopes was also assessed and the results showed that the interactive effects of the pretest and the groups were not significant $(p<0.05)$; therefore, the data supported the hypothesis of equality of the regression slopes since the significance value of the Box's test was more than 0.05. Accordingly, the assumption of homogeneity of variancecovariance matrices was also evaluated. Since all the necessary assumptions for applying the covariance analysis were observed, the data could be used to test the research hypothesis. Furthermore, to analyze the obtained data SPSS-22 was used and one-way analysis of covariance (ANCOVA) was run.

Anxious Thoughts Inventory was developed by Wells in 1994. It includes 22 items that evaluate anxious thoughts. Subscales of this inventory are as follows: social worry, health worry, and meta-worry. This inventory is scored based on a 4-point Likert- scale. The convergence validity of this inventory was assessed using a correlation method. Reliability of this inventory was evaluated by a Cronbach's alpha coefficient which was 0.91 for the whole scale [22].

The experimental group underwent ten 90-minute sessions of mindfulness-based cognitive behavioral anger management therapy in two months. In each session, the necessary training as well as homework assignments and activities were provided. Table 1 summarizes the content of these training sessions [23].

Ethical considerations, including obtaining 
the full consent of the participants, maintaining

the opportunity to abandon the study whenever data confidentiality, and giving the participants they wanted, were strictly observed.

Table 1 The content of mindfulness-based cognitive behavioral anger management therapy

\begin{tabular}{|c|c|}
\hline Training sessions & Content \\
\hline The first session & $\begin{array}{l}\text { Providing some backgrounds and introducing the subjects, providing counseling guidelines, having } \\
\text { an open discussion, and assigning homework }\end{array}$ \\
\hline The second session & $\begin{array}{l}\text { Reviewing what was taught in the last session, checking homework assignments, and practicing the } \\
\text { cognitive-behavioral model }\end{array}$ \\
\hline The third session & $\begin{array}{l}\text { Examining moods, reviewing what was taught in the last session, checking homework assignments, } \\
\text { and practicing the body check out technique }\end{array}$ \\
\hline The fourth session & $\begin{array}{l}\text { Focusing on thoughts, emotions, and behaviors, practicing the sitting meditation technique, having an } \\
\text { open discussion, and assigning homework }\end{array}$ \\
\hline The fifth session & $\begin{array}{l}\text { Practicing the three-minute breathing space technique, having an open discussion, assigning } \\
\text { homework, and reviewing and summarizing what were taught }\end{array}$ \\
\hline The sixth session & $\begin{array}{l}\text { Reviewing homework assignments, practicing the sitting meditation, and introducing the coping } \\
\text { strategies technique }\end{array}$ \\
\hline The seventh session & $\begin{array}{l}\text { Reviewing the homework assignments, practicing meditation, introducing the attitudinal factors } \\
\text { technique, and having an open discussion }\end{array}$ \\
\hline The eighth session & $\begin{array}{l}\text { Introducing the problem-solving technique, having an open discussion, assigning homework, and } \\
\text { reviewing and summarizing }\end{array}$ \\
\hline The ninth session & $\begin{array}{l}\text { Practicing to create a link between cognitive-behavioral and mindfulness models and having an open } \\
\text { discussion }\end{array}$ \\
\hline The tenth session & $\begin{array}{l}\text { Discussing methods of reaching a goal and discussing obstacles and constraints and methods of } \\
\text { dealing with them }\end{array}$ \\
\hline
\end{tabular}

\section{Results}

The students aged between 12 to 15 years old. Table 2 shows means and standard deviations of anxious thoughts scores obtained in the experimental and control groups during the pretest and posttest.

It can be stated that the mean scores of anxious thoughts obtained by the experimental group in the posttest, compared to the control group, was improved.

Table 2 The mean and standard deviation of anxious thoughts across experimental and control groups

\begin{tabular}{lccc}
\hline Group & Test & \multicolumn{2}{c}{ Anxious thoughts } \\
\hline \multirow{2}{*}{ Experimental } & & Mean & SD \\
& Pretest & 63.46 & 1.84 \\
& Posttest & 55.93 & 3.91 \\
Control & Pretest & 59.13 & 5.08 \\
& Posttest & 67.13 & 2.97 \\
\hline
\end{tabular}

Table 3 Results of covariance analysis on the posttest mean scores of anxious thoughts in two groups

\begin{tabular}{lcccccc}
\hline $\begin{array}{l}\text { Source of } \\
\text { variation }\end{array}$ & $\begin{array}{c}\text { Sum of } \\
\text { squares }\end{array}$ & df & $\begin{array}{c}\text { Mean of } \\
\text { squares }\end{array}$ & F & Sig. & $\eta^{2}$ \\
\hline Constant & 189.17 & 1 & 189.17 & 17.25 & 0.05 & 0.39 \\
Pretest & 42.68 & 1 & 42.68 & 3.89 & 0.05 & 0.12 \\
Group & 885.84 & 1 & 885.84 & 80.80 & 0.05 & 0.75 \\
Error & 295.98 & 27 & 10.96 & - & - & - \\
Total & 114870.00 & 30 & - & - & - & - \\
\hline
\end{tabular}

There was a significant difference between the mean scores of anxious thoughts obtained after eliminating the effect of pretest on the posttest
$(F=80.80, p<0.05, \eta 2=0.75)$. Accordingly, the mean score of anxious thoughts obtained by the experimental group in the posttest was 
significantly lower than that by the control group. In other words, it can be stated that mindfulness-based cognitive behavioral anger management therapy significantly decreased anxious thoughts in the experimental group (Table 3).

\section{Discussion}

The results of the current study indicated that the mean score of anxious thoughts obtained by the experimental group was significantly lower than that of the control group after conducting mindfulness-based cognitive behavioral anger management therapy. In other words, it can be noted that mindfulness-based cognitive behavioral anger management therapy significantly decreased anxious thoughts in the experimental group. This finding is consistent with results obtained by the previous studies. Results of a study conducted by Sanders and Akiyama indicated that non-pharmacological treatments, including counseling and psychological therapies based on cognitivebehavioral therapies and stimulation cycles could lead to a decrease in the quality of anxiety [24]. Moreover, Wheless and Fergus found out that cognitive-behavioral techniques and main components of mindfulness were effective in reducing levels of anxiety among people who suffered from anxiety [25]. Furthermore, results of a study carried out by Reid et al., demonstrated that informal cognitivebehavioral techniques, such as cognitive reconstruction and relaxation techniques, could be effective in decreasing and treating social anxiety, obsessive-compulsive disorder, and panic disorder among adolescents [26]. In their study, Romero-Martínez and Moya-Albiol figured out that quality of life and the way of controlling cognitive-Behavioral Therapy could affect anxiety and depression among patients [2]. In the same line, they demonstrated that experiencing emotions rather than ignoring them and focusing on moods and emotional essence affected on identifying anxiety and anxious thoughts $[2,10]$. In addition, Wang et al, found out that the third wave of the cognitivebehavioral therapies based on mindfulness which includes holding several group sessions and then practicing the assignments individually could be effective in decreasing anxious thoughts [27]. The study by Banneyer et al. indicated that the cognitive-behavioral therapy was very useful in the treatment of childhood anxiety disorders and adaptation issues [28]. Moreover, The study by Elsner et al. showed that guided methods, such as establishing relationships, holding training sessions for patients, assessing needs, and performing practical screenings were able to decrease anxiety [29].

Although our study provided useful information, it also had some limitations. In this study, we used convenience sampling; hence, the results are only generalizable to the sampled population. Based on the results of this study, cognitive-behavioral therapy focused on anger management had a significant relationship with anxiety thoughts. So it is suggested that therapists and counselors who work on anger management fields, apply this program to control anxiety and other treatments. It is also suggested that a random sampling method be used to select individuals so that the results can be generalized to the community.

\section{Conclusion}

Adolescence is one of the most stressful periods in any person's life. In this period, students have to deal with high levels of anxiety thoughts due to a number of reasons, including identity seeking, puberty, hypothesis-driven thinking, deductive and ethical reasoning, invincibility, and role-taking. Students experience their greatest academic failures and achievements in their adolescence. According to findings of the present study, training the third wave of mindfulness-based cognitive behavioral anger management therapy, which emerged after psychoanalytic therapies and cognitive-behavioral therapies, can be used to reduce mental injuries and disorders, such as anxiety thoughts, among students. This therapeutic approach can be an appropriate alternative to the treatments used for treating 
mental disorders and illnesses in the present. Further studies are suggested to evaluate the effectiveness of these treatments on different populations and variables. The findings of the current study, due to its therapeutic application, can be used in various organizations such as medical, psychiatric, counseling, and educational centers.

\section{Acknowledgments}

This study was extracted from a Ph.D. dissertation and approved by the Zahedan faculty of psychology and educational sciences ethics committee (ethics code:10920702961005).

\section{Contribution}

Study Design: KHB, MS, AA

Data collection and analysis: KHB

Manuscript preparation: KHB

\section{Conflict of Interest}

"The authors declare that they have no competing interests."

\section{Funding}

The author (s) received no financial support for the research, authorship and/or publication of this article.

\section{References}

1- Shahini M, Shala M, Xhylani P, Gashi S, Borinca I, Erfurth A. Challenging predictions between affective temperaments, depression and anxiety in a Kosovo student community sample. Int J Psychiatry Clin2018; 22(4): 282-88.

2- Romero-Martínez Á, Moya-Albiol L. High anger expression is associated with reduced cortisol awakening response and health complaints in healthy young adults. Span J Psychol2016; 19(19): 20-5

3- Johnstone KM, Kemps E, Chen J. A meta-analysis of universal school-based prevention programs for anxiety and depression in children. Clin Child Fam Psychol Rev2018; 21(4): 466-81.

4- Crocq MA. A history of anxiety: from Hippocrates to DSM. Dialogues Clin Neurosci2015; 17(3): 319-25.

5- Dadsetan P. Developmental psychology. First volume. Tehran: Publication Side; 2008.

6- Danchin M, Gulenc A, Efron D, Sciberras E, Symeonides C, Hiscock H. Trends in prevalence and management of childhood anxiety by Australian pediatricians. Acad Pediatr2019; 19(1): 35-43.

7- Buonocore M, Bosia M, Baraldi MA, et al. Exploring anxiety in schizophrenia: new light on a hidden figure. Psychiatry Res2018; 268: 312-6.

8- Williams KE, Koleva H. Identification and treatment of peripartum anxiety disorders. Obstet Gynecol Clin North Am2018; 45(3): 469-81.

9- D-Urso G, Mantovani A, Patti S, Toscano E. Transcranial direct current stimulation in obsessivecompulsive disorder, posttraumatic stress disorder, and anxiety disorders. J ECT2018; 34(3):172-81.

10- Sahin N, Kasap B, Kirli U, Yeniceri N, Topal Y. Assessment of anxiety-depression levels and perceptions of quality of life in adolescents with dysmenorrhea. Reprod Health2018; 15(1): 13.

11- Malik R, Yaddanpudi S, Panda NB, Kohli A, Mathew PJ. Predictors of pre-operative anxiety in Indian children. Indian J Pediatr2018; 85(7): 504-9.

12- Yamazaki S, Shinohara R, Akiyama Y, et al. The relationship between parenting anxiety in mothers and the resources from which they routinely sought advice: The final" Healthy Parents and Children 21" survey. Nihon Koshu Eisei Zasshi2018; 65(7): 334-8.

13- Liu YY, Liu YQ, Petrini MA. Effect of information of patients' coping style on pregastroscopy anxiety. Gastroenterology Nursing2018; 41(1): 47-58.

14- Lowe SR, Tineo P, Young MN. Perceived discrimination and major depression and generalized anxiety symptoms: in muslim American college students. J Relig Health2018; 9: 1-10.

15- Majdandžić M, de Vente W, Colonnesi C, Bögels SM. Fathers' challenging parenting behavior predicts less subsequent anxiety symptoms in early childhood. Behav Res Ther2018; 109: 18-28.

16- Kim C, Choi H, Ko H, Park CG. Agreement between parent proxy reports and self-reports of adolescent emotional distress. J Sch Nurs2018: 14(2): 125-34.

17- Bilsky SA, Cloutier RM, Bynion TM, Feldner MT, Leen-Feldner EW. An experimental test of the impact of adolescent anxiety on parental sick role reinforcement behavior. Behav Res Ther2018; 109: 37-48.

18- Merz EC, He X, Noble KG. Anxiety, depression, impulsivity, and brain structure in children and adolescents. Neuroimage Clin2018; 20: 243-51.

19- Moriarity DP, McArthur BA, Ellman LM, Coe CL, Abramson LY, Alloy LB. Immunocognitive model of depression secondary to anxiety in adolescents. $J$ Youth Adolesc2018; 47(12): 2625-36.

20- Naderi H, Seyf Naraghi M. Research methods and its evaluation in Humanities (Eds. 6). Tehran: Arasbaran publication; 2017.

21- Wells A, Davies MI. The thought control questionnaire: a measure of individual differences in the control of unwanted thoughts. Behav Res Ther1994; 
32(8): 871-8.

22- Soltani E, Bahrainian SA, Masjedi Arani A, Farhoudian A, Gachkar L. Psychometric properties of the Persian version of the social anxiety-acceptance and action questionnaire. Iran J Psychiatry Behav Sci2016;10(2): e3753.

23- Segal Z, Vincent P, Levitt A. Efficacy of combined, sequentialand crossover psychotherapy and pharmacotherapy in improving outcomes in depression. J Psychiatry Neurosci2002; 27(4): 281-6.

24- Sanders KM, Akiyama T. The vicious cycle of itch and anxiety. Neurosci Biobehav Rev2018; 87: 17-26.

25- Fergus TA, Wheless NE. The attention training technique causally reduces self-focus following worry provocation and reduces cognitive anxiety among selffocused individuals. J Behav Ther Exp Psychiatry2018; 61: 66-71.
26- Reid AM, Guzick AG, Fernandez AG, et al. Exposure therapy for youth with anxiety: Utilization rates and predictors of implementation in a sample of practicing clinicians from across the United States. $J$ Anxiety Disord2018; 58: 8-17.

27- Carey E, Hill F, Devine A, Szücs D. The modified abbreviated math anxiety scale: a valid and reliable instrument for use with children. Front Psychol2017; 8: 11-6.

28- Banneyer KN, Bonin L, Price K, Goodman WK, Storch EA. Cognitive behavioral therapy for childhood anxiety disorders: a review of recent advances. Curr Psychiatry Rep2018; 20 (8): 65-70.

29- Elsner K, Naehrig D, Halkett GK, Dhillon HM. Reduced patient anxiety as a result of radiation therapist-led psychosocial support: a systematic review. J Med Radiat Sci2017; 64(3): 220-31.

\footnotetext{
Copyright(C) 2016 ASP Ins. This open-access article is published under the terms of the Creative Commons Attribution-NonCommercial 4.0 International License which permits Share (copy and redistribute the material in any medium or format) and Adapt (remix, transform, and build upon the material) under the Attribution-NonCommercial terms.
} 